To be published in Optics Letters:

Title: $\quad$ Carbon dioxide absorption spectroscopy with a mid-infrared silicon photonic waveguide Authors: $\quad$ Floria Ottonello-Briano,Carlos Errando-Herranz,Henrik Rödjegård,Hans Martin,Hans Sohl Accepted: 01 November 19

Posted 06 November 19

Doc. ID: $\quad 370397$ 


\title{
Carbon dioxide absorption spectroscopy with a mid-infrared silicon photonic waveguide
}

\author{
Floria Ottonello-Briano ${ }^{1 *}$, Carlos Errando-Herranz ${ }^{1}$, Henrik Rödjegård ${ }^{2}$, \\ Hans MARTIN ${ }^{2}$, Hans SOHLStröm ${ }^{1}$, AND KRISTINn B. GYLFASON ${ }^{1}$ \\ ${ }^{1}$ Micro and Nanosystems, KTH Royal Institute of Technology, Malvinas väg 10, 10044 Stockholm, Sweden \\ ${ }^{2}$ Senseair AB, Stationsgatan 12, 82471 Delsbo, Sweden \\ *Corresponding author: floria@kth.se
}

Compiled November 6, 2019

Carbon dioxide is a vital gas for life on Earth, a waste product of human activities, and widely used in agriculture and industry. Its accurate sensing is therefore of great interest. Optical sensors exploiting the midinfrared light absorption of $\mathrm{CO}_{2}$ provide high selectivity, but their large size and high cost limit their use. Here, we demonstrate $\mathrm{CO}_{2}$ gas sensing at $4.2 \mu \mathrm{m}$ wavelength using an integrated silicon waveguide, featuring a sensitivity to $\mathrm{CO}_{2}$ of $44 \%$ that of free-space sensing. The suspended waveguide is fabricated on a silicon-on-insulator substrate by a single-lithographystep process, and we route it into a mid-infrared photonic circuit for on-chip-referenced gas measurements. Its demonstrated performance and its simple and scalable fabrication make our waveguide ideal for integration in miniaturized $\mathrm{CO}_{2}$ sensors for distributed environmental monitoring, personal safety, medical, and high-volume consumer applications. @ 2019 Optical Society of America

http://dx.doi.org/10.1364/ao.XX.XXXXXX

Carbon dioxide $\left(\mathrm{CO}_{2}\right)$ is an atmospheric trace gas and, being the carbon source in the carbon cycle, it is vital to life on Earth. It is also a waste product of human activities and massively used in agriculture and industry. The atmospheric $\mathrm{CO}_{2}$ concentration is growing at an ever increasing rate and reached $410 \mathrm{ppm}$ in 2018 [1]. Besides affecting Earth's climate [2, 3], elevated $\mathrm{CO}_{2}$ levels increase air pollution mortality [4], and gross leakage of $\mathrm{CO}_{2}$ puts personnel at risk of asphyxiation [5]. Indoors, high $\mathrm{CO}_{2}$ levels deteriorate human cognitive function and decisionmaking [6-8], with consequences spanning from reduced attention and productivity in classrooms and offices [6, 7] to an increased risk for car and airplane accidents [8]. Extensive and accurate sensing of $\mathrm{CO}_{2}$ is therefore crucial.

Optical $\mathrm{CO}_{2}$ sensors would benefit most applications, due to their high selectivity, fast response, and minimal drift, compared to electrochemical and metal-oxide semiconductor-based sensors [9]. However, the adoption of traditional non-dispersive infrared $\mathrm{CO}_{2}$ sensors, with a free-space configuration, is limited by their large size, high cost, and high power consumption.
In contrast, optical $\mathrm{CO}_{2}$ sensors based on integrated photonic waveguides, which allow a light path as long as tens of centimeters to fit in a volume smaller than a few cubic millimeters, could achieve the level of miniaturization and power consumption required for mobile applications.

Despite the advantages of miniaturized optical absorption $\mathrm{CO}_{2}$ sensors, their development has been hindered by the lack of suitable optical components for the mid-infrared (mid-IR) spectral range, where the optical sensing of ambient $\mathrm{CO}_{2}$ with high selectivity and sensitivity is optimal. At wavelengths around $4.26 \mu \mathrm{m}, \mathrm{CO}_{2}$ presents strong isolated absorption peaks that do not overlap with those of other gases commonly present in ambient air, such as water vapor, as shown in Fig. 1 . The recent progress in light sources [11-13], detectors [12-18], and integrated waveguides $[12,13,16,19]$ for the mid-IR is now accelerating the development of on-chip optical $\mathrm{CO}_{2}$ sensors.

To be the core element of miniaturized optical $\mathrm{CO}_{2}$ sensors, photonic waveguides must fulfill two key requirements. They must support light modes at $4.2 \mu \mathrm{m}$ wavelength with a large portion of the field outside the waveguide core material, to enable

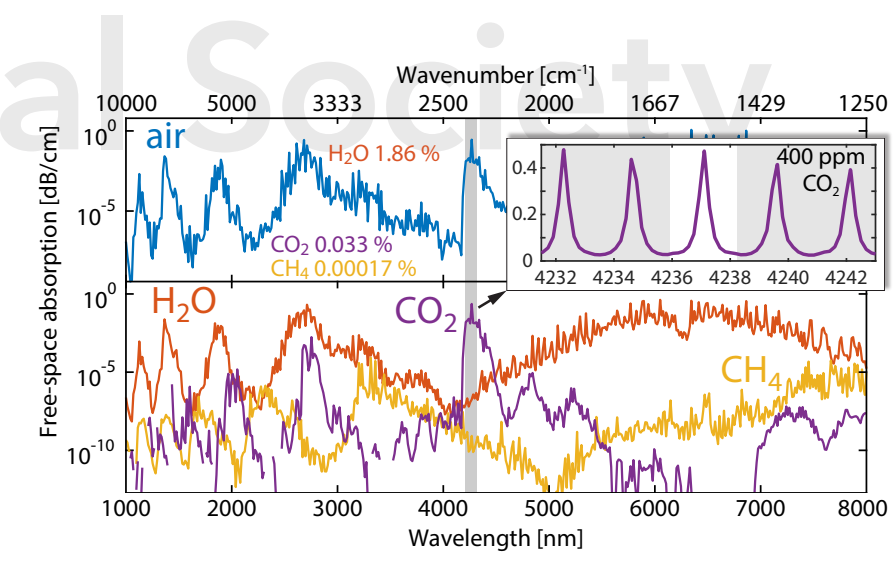

Fig. 1. Absorption spectra of typical air at $296 \mathrm{~K}$ and $1 \mathrm{~atm}$ and its mid-IR-active constituents: water vapor, carbon dioxide, and methane [10]. Inset: zoom-in of five peaks in the fundamental asymmetric stretching band of $\mathrm{CO}_{2}$. Highlighted, the range we employ for absorption spectroscopy with our waveguide. 

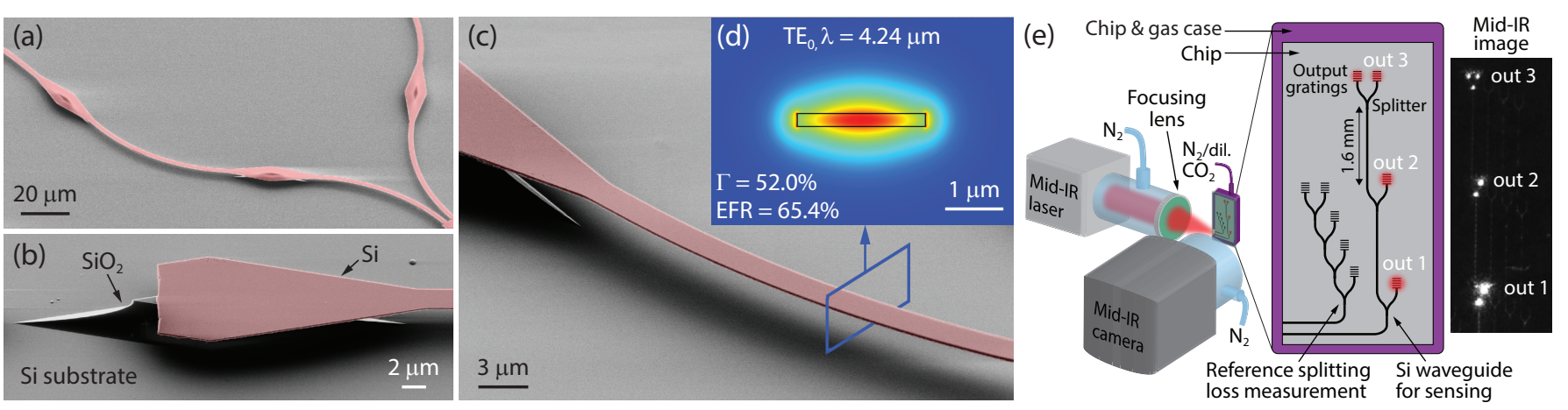

Fig. 2. (a), (b), (c) False-color SEM images of the fabricated Si photonic waveguide. (a) Waveguides branching out from a splitter. (b) A support structure where the $\mathrm{Si}$ waveguide was partially removed to expose the $\mathrm{SiO}_{2}$ pillar. (c) A close-up view of the suspended waveguide. (d) Cross-sectional FEM simulation of the waveguide, displaying the electric field profile of the de-confined fundamental TE mode. (e) Schematic of the setup used for $\mathrm{CO}_{2}$ sensing, including a sample mid-IR image of the operating waveguide.

interaction with the gas, and they should have a low base propagation loss, as this limits the applicable waveguide length. The ratio between these characteristics fully determines the sensing performance of the waveguide, and is expressed by the figure of merit FOM $=\Gamma / \alpha$, introduced by Kita et al. [20]. Here, $\alpha$ is the waveguide base attenuation coefficient, including all losses not due to $\mathrm{CO}_{2}$ absorption, such as material, scattering, curvature, and substrate losses. $\Gamma=\partial n_{\text {mode }} / \partial n_{\text {clad }}$, where $n_{\text {mode }}$ is the light mode's effective index, is the external confinement factor expressing the waveguide's sensitivity to changes in the cladding's refractive index $n_{\text {clad }}$ [20-22]. Contrarily to the evanescent field ratio (EFR), i.e. the portion of optical power propagating outside the waveguide core, $\Gamma$ correctly describes the sensitivity of any waveguide, including those with high core-cladding refractive index contrast [22]. The FOM, in conjunction with the waveguide length and the signal-to-noise ratio of the measurement setup, determines the achievable limit of detection of the system.

A variety of integrated waveguides for the mid-IR have been presented $[12,13,16,19]$. A particularly attractive waveguide material is silicon $(\mathrm{Si})$, because it combines a large transparency window in the mid-IR, wide availability, and a well-established mass production infrastructure. Si-waveguide-based sensing of methane has been demonstrated at $1.65 \mu \mathrm{m}$ wavelength [23]. Sensing of $\mathrm{CO}_{2}$ at $4.2 \mu \mathrm{m}$, however, remains challenging, because the commonly used silicon dioxide $\left(\mathrm{SiO}_{2}\right)$ cladding is optically absorbing at that wavelength. Siebert and Müller [24] proposed carving $\mathrm{Si}$ waveguides for $\mathrm{CO}_{2}$ sensing out of bulk $\mathrm{Si}$. However, their fabrication process is complex, and their waveguide design leads to a large etched sidewall surface, resulting in high scattering loss. Moreover, the highest EFR achievable is only $24 \%$. More recently, Ranacher et al. showed $\mathrm{CO}_{2}$ sensing with a poly-crystalline $\mathrm{Si}$ strip waveguide on an $\mathrm{SiO}_{2}$ cladding, with a simulated EFR of $7.4 \%$ [25], and the same waveguide on a partially suspended silicon nitride membrane on $\mathrm{SiO}_{2}$-on-Si support structures, formed by through-wafer back-side etching, with a simulated EFR of $10.7 \%$ [26].

Here, we present a partially suspended mid-IR Si waveguide with a high external confinement factor, and use it to perform on-chip absorption spectroscopy of $\mathrm{CO}_{2}$ concentrations down to $0.1 \%$ at $\lambda=4.24 \mu \mathrm{m}$ wavelength. We demonstrate that the $\Gamma$, and hence the sensitivity to $\mathrm{CO}_{2}$, of our waveguide is $44 \%$ that of free-space sensing.

Our photonic waveguide, shown in Fig. $2(\mathrm{a}-\mathrm{c})$, is a Si beam partially suspended $3 \mu \mathrm{m}$ above the Si handle substrate and sup- ported by tapered $\mathrm{SiO}_{2}$ pillars. The waveguide is $220 \mathrm{~nm}$ thick and $2.2 \mu \mathrm{m}$ wide in its suspended sections. At the pillars, spaced $83 \mu \mathrm{m}$ from each other, it widens to $9 \mu \mathrm{m}$ with $17 \mu \mathrm{m}$-long linear tapers, i.e. $11.5^{\circ}$ tapers. According to bidirectional eigenmode expansion simulations, the support structures have an insertion loss of $0.025 \mathrm{~dB}$ each, and are thus the main contributor to the waveguide propagation loss. The absence of a continuous solid bottom cladding and the large separation from the substrate limit the substrate leakage loss to a simulated $0.12 \mathrm{~dB} / \mathrm{cm}$ and make the waveguide vertically symmetric, thus allowing light guiding with a very small core thickness, and hence low confinement of the propagating light. These features result in a high $\Gamma$, negligible material absorption and substrate leakage losses, and maximized mode overlap with the analyte gas in all directions. According to finite-element-method (FEM) simulations, the supported quasi-TE fundamental mode at $4.24 \mu \mathrm{m}$ wavelength (Fig. 2 (d)) has an EFR of $65.4 \%$ and an external confinement factor $\Gamma$ of $52.0 \%$. Taking into account the support structures, the simulated effective EFR and $\Gamma$ are $63.2 \%$ and $46.3 \%$, respectively. We note that the high value of $\Gamma$ results from the low confinement of the light and not from narrow-band effects such as slow light enhancement or resonance. Furthermore, the waveguide features a small footprint and can be routed to form photonic circuits. We designed a waveguide circuit layout, shown in Fig. 2 (e), for fully on-chip-referenced measurements, to avoid characterization errors due to the $\mathrm{CO}_{2}$ in ambient air. After an edge-coupled input waveguide section, three outputs branch out with symmetrical 1x2 multi-mode interference (MMI) splitters at regular length intervals of $1.6 \mathrm{~mm}$, and terminate with surface grating couplers. The MMI splitters are rectangular, non-tapered, $8.4 \mu \mathrm{m}$ wide and $15 \mu \mathrm{m}$ long. Fabrication error resulted in a residual $\mathrm{SiO}_{2}$ pillar underneath each $\mathrm{MMI}$ and rough sidewalls, which add a significant loss. The grating couplers are fully suspended, through etched, and apodized to minimize backward reflection. Their simulated back-reflection is $5 \%$, and the upward radiation efficiency is $45 \%$.

The waveguide circuit was fabricated on a commercial siliconon-insulator (SOI) substrate with a $220 \mathrm{~nm}$ Si device layer and a $3 \mu \mathrm{m} \mathrm{SiO} 2$ buried oxide (BOX) layer by a single electron-beam lithography step, dry etching of the $\mathrm{Si}$, wet etching of the $\mathrm{SiO}_{2}$, and cleaving. We used electron-beam lithography because of its rapid turnaround time, but the minimum feature size in the circuit is compatible with stepper photolithography.

We characterized the $\mathrm{CO}_{2}$ sensing performance of our 

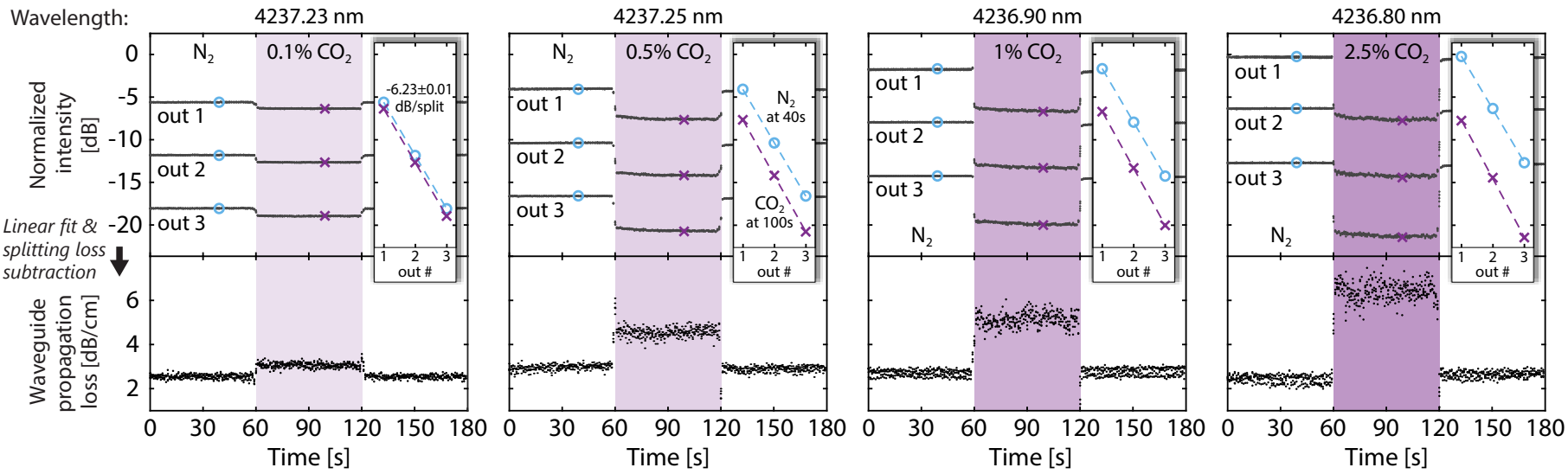

Fig. 3. Four sample measurements of $0.1 \%, 0.5 \%, 1 \%$, and $2.5 \% \mathrm{CO}_{2}$ in $\mathrm{N}_{2}$. The top panels show the waveguide output intensities, while the bottom panels show the extracted propagation loss. The insets show the linear fit of the intensities for two sample frames.

photonic waveguide with the setup shown in Fig. 2 (e). We focused $4.24 \mu \mathrm{m}$ continuous-wave linearly polarized light from a distributed-feedback quantum cascade tunable laser (MLQD4232, Thorlabs, USA) with single-wavelength emission onto the input facet of the waveguide. We placed the waveguide chip inside a steel case with a mid-IR-transparent window that allowed the visualization of the chip surface by a mid-IR camera (A6700sc, FLIR, USA) equipped with a cooled InSb detector and a $1 \times$ macro lens. The chip case also had an inlet and an outlet that enabled controlled gas injection and a steady flow inside the case. The mid-IR camera aided the alignment of the waveguide input to the focused light for in-coupling and detected the output signal from the grating couplers. We alternately injected nitrogen $\left(\mathrm{N}_{2}\right)$ and dilutions of $\mathrm{CO}_{2}$ in $\mathrm{N}_{2}$, purchased pre-mixed, in concentrations of $0.1 \%, 0.5 \%, 1 \%$, and $2.5 \%$ in 1 min intervals at a flow rate of $600 \mathrm{~mL} / \mathrm{min}$. For each $\mathrm{CO}_{2}$ concentration, we repeated the three-minute $\mathrm{N}_{2}-\mathrm{CO}_{2}-\mathrm{N}_{2}$ measurement at different wavelengths, calibrated with an accuracy of $\pm 0.01 \mathrm{~nm}$, across the $\mathrm{CO}_{2}$ absorption peak highlighted in the inset of Fig. 1. To reduce light absorption by the atmospheric $\mathrm{CO}_{2}$ along the free-space path between the laser head and the focusing lens and between the chip case and the camera, we enclosed these sections in brass tubes and continuously flushed those with $\mathrm{N}_{2}$.

Fig. 3 shows the results of four sample measurements, one for each $\mathrm{CO}_{2}$ concentration tested. The top panels show the intensity time traces of the three waveguide outputs, including all recorded frames. Here, the intensity drop during $\mathrm{CO}_{2}$ injection results from light absorption along the entire light path, i.e. along the waveguide, including the input section before the first output, and the free-space sections in the setup, where residual ambient $\mathrm{CO}_{2}$ is present despite the $\mathrm{N}_{2}$ flushing. By extracting the decay rate of the light intensity along the waveguide from the three outputs, as shown in the insets of Fig. 3, we continuously measured the waveguide propagation loss in a real-time cut-back measurement. We accounted for the splitting loss, measured using a reference waveguide circuit with no additional waveguide length between splitters (Fig. 2 (e)) to be $(5.8 \pm 0.2) \mathrm{dB} /$ split. The measured propagation loss is displayed in the bottom panels of Fig. 3. The propagation loss during $\mathrm{N}_{2}$ injection, i.e. the waveguide base loss, is $(3 \pm 1) \mathrm{dB} / \mathrm{cm}$. The increase in the loss during $\mathrm{CO}_{2}$ injection, clearly visible at all tested concentrations, is the excess loss caused exclusively by absorption along the straight waveguide sections between grating outputs. The response time is less than $2 \mathrm{~s}$ and limited

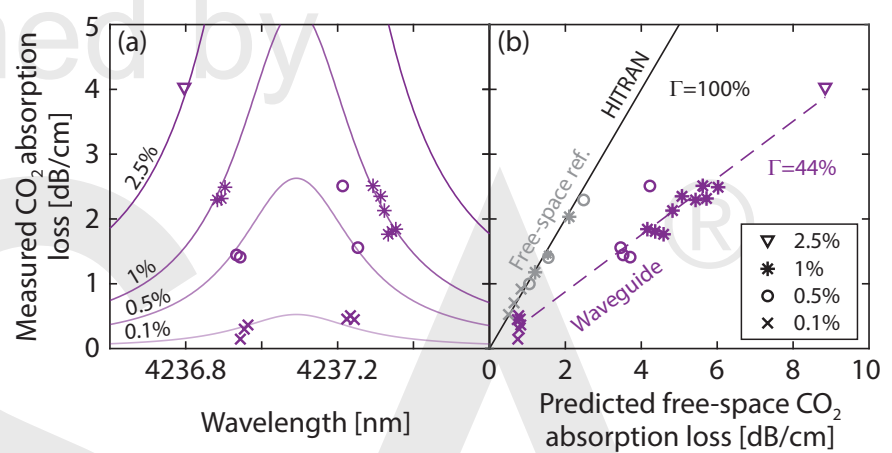

Fig. 4. Measured excess waveguide propagation loss due to $\mathrm{CO}_{2}$, compared to the free-space $\mathrm{CO}_{2}$ absorption loss [10].

(a) Waveguide $\mathrm{CO}_{2}$ loss spectrum (markers) and $44 \%$ downscaled HITRAN free-space spectrum (solid lines).

(b) Waveguide $\mathrm{CO}_{2}$ loss as a function of the free-space loss.

The gray markers show our free-space reference measurement.

by the manual gas switching and by the gas exchange time in the chip case. The difference between the time-averaged propagation loss during $\mathrm{N}_{2}$ injection and the one during $\mathrm{CO}_{2}$ injection is the waveguide $\mathrm{CO}_{2}$ absorption loss.

Fig. 4 shows the waveguide $\mathrm{CO}_{2}$ absorption loss for all concentrations and wavelengths measured. We compare the measured waveguide $\mathrm{CO}_{2}$ absorption loss with the predicted freespace $\mathrm{CO}_{2}$ absorption loss at corresponding pressure and temperature, as listed in the HITRAN database [10] and confirmed by our free-space reference measurement. We find that the $\Gamma$ of our waveguide, i.e. its sensitivity to $\mathrm{CO}_{2}$, is $(43.85 \pm 0.01) \%$ that of free-space, a value close to the simulated $46.3 \%$. The measured FOM of our waveguide is thus $(0.6 \pm 0.3) \mathrm{cm}$. The standard deviation of the measured waveguide propagation loss in $\mathrm{N}_{2}$ (Fig. 3) indicates that the smallest loss change measurable in our setup is $0.18 \mathrm{~dB}$, corresponding to a $\mathrm{CO}_{2}$ concentration change of $350 \mathrm{ppm}$. According to the measured FOM, the optimal length $[20,24]$ for our waveguide to sense present-day atmospheric levels of $\mathrm{CO}_{2}$, i.e. $400 \mathrm{ppm}$, is $1.4 \mathrm{~cm}$.

In Table 1, we compare our waveguide to other relevant integrated gas-sensing waveguides. Our waveguide features the highest theoretical and experimentally demonstrated $\Gamma$ and FOM amongst all the listed waveguides.

We note that Ranacher et al. $[25,26]$ measured a $\Gamma$ consistently 
Table 1. Comparison of reported gas-sensing waveguides.

\begin{tabular}{|c|c|c|c|c|c|c|c|c|c|}
\hline & \multirow[b]{2}{*}{ Pol. } & \multirow[b]{2}{*}{$\begin{array}{c}\lambda \\
{[\mu \mathrm{m}]}\end{array}$} & \multirow[b]{2}{*}{ Gas } & \multicolumn{3}{|c|}{ Simulated } & \multicolumn{3}{|c|}{ Measured } \\
\hline & & & & $\begin{array}{l}\text { Intrinsic } \\
\text { mode loss } \\
{[\mathrm{dB} / \mathrm{cm}]}\end{array}$ & $\begin{array}{c}\Gamma \\
{[\%]}\end{array}$ & $\begin{array}{c}\text { FOM } \\
\Gamma / \alpha \\
{[\mathrm{cm}]}\end{array}$ & $\begin{array}{c}\text { Waveguide } \\
\text { base loss } \alpha_{d B} \\
{[\mathrm{~dB} / \mathrm{cm}]}\end{array}$ & $\begin{array}{c}\Gamma \\
{[\%]}\end{array}$ & $\begin{array}{c}\text { FOM } \\
\Gamma / \alpha \\
{[\mathrm{cm}]}\end{array}$ \\
\hline $\begin{array}{l}\text { This } \\
\text { work }\end{array}$ & $\mathrm{TE}$ & 4.24 & $\mathrm{CO}_{2}$ & 2.9 & 46.3 & 0.69 & $3 \pm 1$ & 44 & $0.6 \pm 0.3$ \\
\hline [25] & $\mathrm{TE}$ & 4.23 & $\mathrm{CO}_{2}$ & 4.4 & 10.8 & 0.11 & $4.0^{\ddagger}$ & 14 & 0.15 \\
\hline [26] & $\mathrm{TE}$ & 4.23 & $\mathrm{CO}_{2}$ & 7.6 & 11.6 & 0.07 & - & 19.5 & - \\
\hline [23] & TM & 1.65 & $\mathrm{CH}_{4}$ & 1.7 & 28.3 & 0.71 & 2 & 25.4 & 0.55 \\
\hline
\end{tabular}

higher than the simulated one. This might be caused by the absorption and subsequent release of $\mathrm{CO}_{2}$ by the plastic tubing and chip case used in the experiments. Such memory effects are particularly relevant when injecting the $\mathrm{CO}_{2}$ mixtures in order of decreasing concentration, and result in higher $\mathrm{CO}_{2}$ levels than intended. Ultimately, the performance of these waveguides is limited by the high intrinsic mode loss caused by the mid-IR absorption of the $\mathrm{SiO}_{2}$ cladding and large support structures. $\mathrm{SiO}_{2}$ absorption at $4.23 \mu \mathrm{m}$ wavelength is, in fact, $54 \mathrm{~dB} / \mathrm{cm} \mathrm{[27].}$

Tombez et al. [23] achieved a high FOM in methane $\left(\mathrm{CH}_{4}\right)$ sensing by probing an overtone absorption band of $\mathrm{CH}_{4}$ using the fundamental TM-polarized mode at $1.65 \mu \mathrm{m}$ wavelength. For their waveguide design, and theoretically for all the listed waveguides, the TM mode is less confined than the TE mode, thus more sensitive, but also lossier. Tombez et al. can exploit the TM mode while keeping the waveguide base loss low because they employ a wavelength at which the $\mathrm{SiO}_{2}$ bottom cladding features low absorption. Such strategy does not work at longer wavelengths, at which the TM mode's base loss increases dramatically. Additionally, the mode size increases with the wavelength, and requires increasing the spacing between the waveguide and a high-refractive-index substrate to limit substrate leakage loss.

We achieve a high $\Gamma$ with the fundamental TE mode thanks to the small waveguide thickness, and a potentially low base loss thanks to the almost complete removal of the $3 \mu$ m-thick $\mathrm{SiO}_{2}$ BOX layer. The intrinsic loss could be lowered by optimizing the support structure design and increasing their pitch. Furthermore, a higher-quality fabrication process, possibly including thermal oxidation and selective oxide etching to smoothen the waveguide surfaces, could further reduce the loss. Since the etched sidewalls constitute only one tenth of the waveguide surface, our design may achieve very low scattering losses.

In conclusion, we have demonstrated the optical absorption spectroscopy of $\mathrm{CO}_{2}$ concentrations down to $0.1 \%$ using a $3.2 \mathrm{~mm}$-long low-confinement $\mathrm{Si}$ photonic waveguide for $4.24 \mu \mathrm{m}$ wavelength. The waveguide was fabricated on an SOI platform with a single lithography step. The waveguide, intrinsically broadband, can operate in conjunction with both broadand narrow-band sources and detectors. It has a small footprint and can easily be routed to form mid-IR photonic circuits, potentially including components such as resonant cavities and spectral filters. By integrating MMI splitters, we implemented for the first time a waveguide circuit for on-chip-referenced gas measurements, to eliminate errors due to the ambient $\mathrm{CO}_{2}$ and ensure that the characterized sensing performance is ascribable only to the waveguide. In this way, we have demonstrated that the $\Gamma$, and hence the sensitivity to gas, of our waveguide is $44 \%$ that of free-space sensing, and its FOM is $0.6 \mathrm{~cm}$. Compared to previous mid-IR gas-sensing waveguides, our waveguide exhibits the highest external confinement factor and a four-fold improved FOM. This demonstrated performance and the simple, cost-effective, and scalable fabrication make our integrated photonic waveguide ideal for mass production and large-scale adoption. It has the potential to become the choice component for an increasingly broad range of applications, such as portable and distributed environmental monitoring, and high-volume medical and consumer applications.

Funding. This work was partially funded by grants from VINNOVA (2016-02328 and 2017-05108), SLL (20150910), and SSF (GMT14-0071).

Disclosures. FOB, HS, KBG: (P), HR, HM: Senseair AB (E).

\section{REFERENCES}

1. R. F. Keeling and C. D. Keeling, "Scripps CO2 Program Data," (2017).

2. A. A. Lacis, G. A. Schmidt, D. Rind, and R. A. Ruedy, Science 330, 356 (2010).

3. H. D. Matthews, N. P. Gillett, P. A. Stott, and K. Zickfeld, Nature 459, 829 (2009).

4. M. Z. Jacobson, Geophys. Res. Lett. 35 (2008).

5. A. Guais, G. Brand, L. Jacquot, M. Karrer, S. Dukan, G. Grévillot, T. J. Molina, J. Bonte, M. Regnier, and L. Schwartz, Chem. Res. Toxicol. 24, 2061 (2011)

6. U. Satish, M. J. Mendell, K. Shekhar, T. Hotchi, D. Sullivan, S. Streufert, and W. J. Fisk, Environ. Heal. Perspect. 120, 1671 (2012).

7. J. G. Allen, P. MacNaughton, U. Satish, S. Santanam, J. Vallarino, and J. D. Spengler, Environ. Heal. Perspect. 124, 805 (2016).

8. J. G. Allen, P. MacNaughton, J. G. Cedeno-Laurent, X. Cao, S. Flanigan, J. Vallarino, F. Rueda, D. Donnelly-McLay, and J. D. Spengler, J. Expo. Anal. Environ. Epidemiol. p. 1 (2018).

9. J. Hodgkinson and R. P. Tatam, Meas. Sci. Technol. 24, 012004 (2013).

10. I. E. Gordon, L. S. Rothman, C. Hill, R. V. Kochanov, Y. Tan et al., J. Quant. Spectrosc. Radiat. Transf. 203, 3 (2017).

11. D. Jung, S. Bank, M. L. Lee, and D. Wasserman, J. Opt. 19, 123001 (2017).

12. H. Lin, Z. Luo, T. Gu, L. C. Kimerling, K. Wada, A. Agarwal, and J. Hu, Nanophotonics. 7 (2017).

13. J. Fedeli and S. Nicoletti, Proc. IEEE 106, 1 (2018).

14. A. Tittl, A.-K. U. Michel, M. Schäferling, X. Yin, B. Gholipour, L. Cui, M. Wuttig, T. Taubner, F. Neubrech, and H. Giessen, Adv. Mater. 27, 4597 (2015).

15. Z. Cheng, C. Qin, F. Wang, H. He, and K. Goda, Front. Optoelectron. 9, 259 (2016).

16. T. Hu, B. Dong, X. Luo, T.-Y. Liow, J. Song, C. Lee, and G.-Q. Lo, Photon. Res. 5, 417 (2017).

17. S. Deckoff-Jones, H. Lin, D. M. Kita, H. Zheng, D. Li, W. Zhang, and J. Hu, J. Opt. 20 (2018)

18. L. Huang, B. Dong, X. Guo, Y. Chang, N. Chen, X. Huang, W. Liao, C. Zhu, H. Wang, C. Lee, and K.-W. Ang, ACS Nano (2018).

19. Y. Zou, S. Chakravarty, C.-J. Chung, X. Xu, and R. T. Chen, Photon. Res. 6, 254 (2018).

20. D. M. Kita, J. Michon, S. G. Johnson, and J. Hu, Optica. 5, 1046 (2018).

21. G. J. Veldhuis, O. Parriaux, H. J. W. M. Hoekstra, and P. V. Lambeck, J. Light. Technol. 18, 677 (2000).

22. J. T. Robinson, K. Preston, O. Painter, and M. Lipson, Opt. Express 16, 16659 (2008).

23. L. Tombez, E. J. Zhang, J. S. Orcutt, S. Kamlapurkar, and W. M. J. Green, Optica 4, 1322 (2017).

24. R. Siebert and J. Müller, Sens. Actuator A Phys. 119, 138 (2005).

25. C. Ranacher, C. Consani, N. Vollert, A. Tortschanoff, M. Bergmeister, T. Grille, and B. Jakoby, IEEE Photon. J 10, 1 (2018).

26. C. Ranacher, C. Consani, A. Tortschanoff, R. Jannesari, M. Bergmeister, T. Grille, and B. Jakoby, Sens. Actuator A Phys. 277, 117 (2018).

27. J. Kischkat, S. Peters, B. Gruska, M. Semtsiv, M. Chashnikova et al., Appl. Opt. 51, 6789 (2012). 


\section{FULL REFERENCES}

1. R. F. Keeling and C. D. Keeling, "Scripps CO2 Program Data," http://doi.org/10.6075/J0542KSG (2017).

2. A. A. Lacis, G. A. Schmidt, D. Rind, and R. A. Ruedy, "Atmospheric CO2: Principal Control Knob Governing Earth's Temperature," Science. 330, 356-359 (2010).

3. H. D. Matthews, N. P. Gillett, P. A. Stott, and K. Zickfeld, "The proportionality of global warming to cumulative carbon emissions," Nature. 459, 829-832 (2009).

4. M. Z. Jacobson, "On the causal link between carbon dioxide and air pollution mortality," Geophys. Res. Lett. 35 (2008).

5. A. Guais, G. Brand, L. Jacquot, M. Karrer, S. Dukan, G. Grévillot, T. J. Molina, J. Bonte, M. Regnier, and L. Schwartz, "Toxicity of Carbon Dioxide: A Review," Chem. Res. Toxicol. 24, 2061-2070 (2011).

6. U. Satish, M. J. Mendell, K. Shekhar, T. Hotchi, D. Sullivan, S. Streufert, and W. J. Fisk, "Is CO2 an Indoor Pollutant? Direct Effects of Lowto-Moderate $\mathrm{CO} 2$ Concentrations on Human Decision-Making Performance," Environ. Heal. Perspect. 120, 1671-1677 (2012).

7. J. G. Allen, P. MacNaughton, U. Satish, S. Santanam, J. Vallarino, and J. D. Spengler, "Associations of Cognitive Function Scores with Carbon Dioxide, Ventilation, and Volatile Organic Compound Exposures in Office Workers: A Controlled Exposure Study of Green and Conventional Office Environments," Environ. Heal. Perspect. 124, 805-812 (2016).

8. J. G. Allen, P. MacNaughton, J. G. Cedeno-Laurent, X. Cao, S. Flanigan, J. Vallarino, F. Rueda, D. Donnelly-McLay, and J. D. Spengler, "Airplane pilot flight performance on 21 maneuvers in a flight simulator under varying carbon dioxide concentrations," J. Expo. Anal. Environ. Epidemiol. p. 1 (2018).

9. J. Hodgkinson and R. P. Tatam, "Optical gas sensing: A review," Meas. Sci. Technol. 24, 012004 (2013).

10. I. E. Gordon, L. S. Rothman, C. Hill, R. V. Kochanov, Y. Tan, P. F. Bernath, M. Birk, V. Boudon, A. Campargue, K. V. Chance, B. J. Drouin, J. M. Flaud, R. R. Gamache, J. T. Hodges, D. Jacquemart, V. I. Perevalov, A. Perrin, K. P. Shine, M. A. H. Smith, J. Tennyson, G. C. Toon, H. Tran, V. G. Tyuterev, A. Barbe, A. G. Császár, V. M. Devi, T. Furtenbacher, J. J. Harrison, J. M. Hartmann, A. Jolly, T. J. Johnson, T. Karman, I. Kleiner, A. A. Kyuberis, J. Loos, O. M. Lyulin, S. T. Massie, S. N. Mikhailenko, N. Moazzen-Ahmadi, H. S. P. Müller, O. V. Naumenko, A. V. Nikitin, O. L. Polyansky, M. Rey, M. Rotger, S. W. Sharpe, K. Sung, E. Starikova, S. A. Tashkun, J. V. Auwera, G. Wagner, J. Wilzewski, P. Wcisło, S. Yu, and E. J. Zak, "The HITRAN2016 molecular spectroscopic database," J. Quant. Spectrosc. Radiat. Transf. 203, 3-69 (2017).

11. D. Jung, S. Bank, M. L. Lee, and D. Wasserman, "Next-generation mid-infrared sources," J. Opt. 19, 123001 (2017).

12. H. Lin, Z. Luo, T. Gu, L. C. Kimerling, K. Wada, A. Agarwal, and J. Hu, "Mid-infrared integrated photonics on silicon: A perspective," Nanophotonics. 7 (2017).

13. J. Fedeli and S. Nicoletti, "Mid-Infrared (Mid-IR) Silicon-Based Photonics," Proc. IEEE 106, 1-11 (2018).

14. A. Tittl, A.-K. U. Michel, M. Schäferling, X. Yin, B. Gholipour, L. Cui, M. Wuttig, T. Taubner, F. Neubrech, and H. Giessen, "A Switchable Mid-Infrared Plasmonic Perfect Absorber with Multispectral Thermal Imaging Capability," Adv. Mater. 27, 4597-4603 (2015).

15. Z. Cheng, C. Qin, F. Wang, H. He, and K. Goda, "Progress on mid-IR graphene photonics and biochemical applications," Front. Optoelectron. 9, 259-269 (2016).

16. T. Hu, B. Dong, X. Luo, T.-Y. Liow, J. Song, C. Lee, and G.-Q. Lo, "Silicon photonic platforms for mid-infrared applications," Photon. Res. 5, 417-430 (2017).

17. S. Deckoff-Jones, H. Lin, D. M. Kita, H. Zheng, D. Li, W. Zhang, and $\mathrm{J}$. Hu, "Chalcogenide glass waveguide-integrated black phosphorus mid-infrared photodetectors," J. Opt. 20 (2018).

18. L. Huang, B. Dong, X. Guo, Y. Chang, N. Chen, X. Huang, W. Liao, C. Zhu, H. Wang, C. Lee, and K.-W. Ang, "Waveguide-Integrated Black Phosphorus Photodetector for Mid-Infrared Applications," ACS Nano (2018).

19. Y. Zou, S. Chakravarty, C.-J. Chung, X. Xu, and R. T. Chen, "Mid- infrared silicon photonic waveguides and devices [Invited]," Photon. Res. 6, 254-276 (2018).

20. D. M. Kita, J. Michon, S. G. Johnson, and J. Hu, "Are slot and subwavelength grating waveguides better than strip waveguides for sensing?" Optica. 5, 1046-1054 (2018).

21. G. J. Veldhuis, O. Parriaux, H. J. W. M. Hoekstra, and P. V. Lambeck, "Sensitivity enhancement in evanescent optical waveguide sensors," J. Light. Technol. 18, 677-682 (2000).

22. J. T. Robinson, K. Preston, O. Painter, and M. Lipson, "First-principle derivation of gain in high-index-contrast waveguides," Opt. Express 16 , 16659-16669 (2008).

23. L. Tombez, E. J. Zhang, J. S. Orcutt, S. Kamlapurkar, and W. M. J. Green, "Methane absorption spectroscopy on a silicon photonic chip," Optica 4, 1322-1325 (2017).

24. R. Siebert and J. Müller, "Infrared integrated optical evanescent field sensor for gas analysis - Part I System design," Sens. Actuator A Phys. 119, 138-149 (2005).

25. C. Ranacher, C. Consani, N. Vollert, A. Tortschanoff, M. Bergmeister, T. Grille, and B. Jakoby, "Characterization of Evanescent Field Gas Sensor Structures Based on Silicon Photonics," IEEE Photon. J 10, 1-14 (2018)

26. C. Ranacher, C. Consani, A. Tortschanoff, R. Jannesari, M. Bergmeister, T. Grille, and B. Jakoby, "Mid-infrared absorption gas sensing using a silicon strip waveguide," Sens. Actuator A Phys. 277, 117-123 (2018).

27. J. Kischkat, S. Peters, B. Gruska, M. Semtsiv, M. Chashnikova, M. Klinkmüller, O. Fedosenko, S. Machulik, A. Aleksandrova, G. Monastyrskyi, Y. Flores, and W. T. Masselink, "Mid-infrared optical properties of thin films of aluminum oxide, titanium dioxide, silicon dioxide, aluminum nitride, and silicon nitride," Appl. Opt. 51, 6789-6798 (2012).

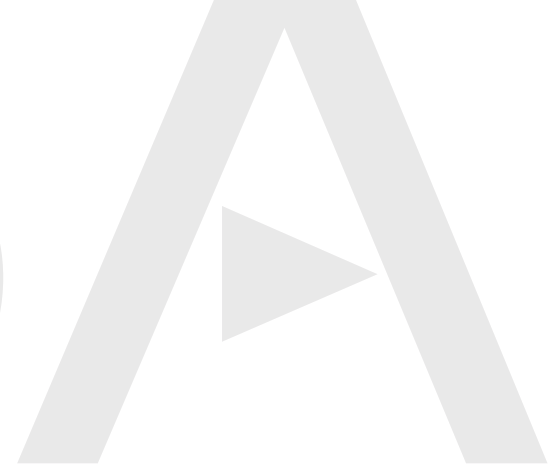

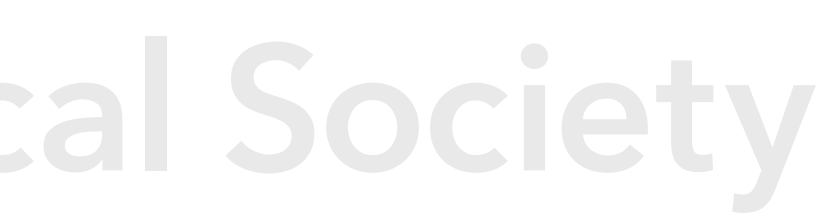

